\title{
On the effect of the physical structure of cement on shrinkage of cementitious materials
}

\author{
Hossein Karimi ${ }^{1, *}$, Qingliang $\mathrm{Yu}^{1}$, and H.J.H. Brouwers ${ }^{1}$ \\ ${ }^{1}$ Department of the Built Environment, Eindhoven University of Technology, P.O. Box 513, 5600 MB Eindhoven, the Netherlands
}

\begin{abstract}
The physical structure of cement is of pivotal importance in the study of volumetric stability and cracking of concrete. While most of efforts in the category of crack mitigation of concrete have been devoted to the incorporation of sophisticated chemical admixtures into concrete mixtures, less attention has been paid to the fact that the modification of cement structure can be considered as a sustainable solution to this problem. This study aims to investigate the effect of the modification of the physical structure of cement on workability, early-age strength and autogenous shrinkage of cement pastes. The results show that the modification of cement physical structure can be used as a sustainable route to reduce shrinkage of cementitious materials.
\end{abstract}

\section{Introduction}

Concrete is by far, the most widely-used construction material on our planet. This high consumption rate has led to a significant demand for cement since it constitutes almost one-third of the volume of concrete. Normal concrete (NC) has inferior mechanical properties and is susceptible to cracking due to shrinkage. Realizing and modifying multi-scale processes resulting in shrinkage of concrete can be a crucial step toward improving this shortcoming. Hence, this approach has received great attention in recent years. Extensive multi-phase studies have been done on shrinkage reducing admixtures (SRA) such as monoalcohols [1], [2], glycols [2]-[6], polyoxyalkylene glycol alkyl ethers [7], or other nonionic surfactant structures [8] to control capillary pressure within pores and decrease the volume change in concrete. Shrinkage compensating admixtures (SCA) of K, M, S, and $\mathrm{G}$ type [9] and high-quality lightly burnt magnesium oxide [9] are other categories of materials that have been introduced to produce initial expansion in order to offset strains caused by shrinkage in concrete. Permeability reducing admixtures (PRA) [10], [11] and superabsorbent polymers [12], [13] have also shown promising results in terms of volume control and crack mitigation of concrete. There have also been studies on the effect of a combination of two or more types of chemical admixtures to make crack-free concrete [14]. However, in spite of the fact that the addition chemical admixtures can help to alleviate cracking in concrete, less attention has been paid to the physical structure of cement as a measure to control both hydration kinetics and pore structure in order to prevent tensile stresses induced by cement hydration just from the beginning.

The physical structure of cement is of pivotal importance in the study of volume-change and cracking of concrete and is controlled by final grinding [15]. Although cement grinding is not a very sophisticated process, it should be well controlled in terms of cement fineness and the temperature within the ball mill [15]. The final grinding has two important effects on the fabricated cement [15]: on the one hand, it affects both reactivity and rheology of cement and on the other hand, it is the last chance to modify cement properties before its introduction to the market. It should also be noted that increasing the fineness of cement particles to the values smaller than $1 \mu \mathrm{m}$, leads to higher inter-particulate adhesive forces which can lead to agglomeration [16].

There has been a trend toward finer cements over the last century. Such a trend well-suits the fast schedules of the construction industry. However, some applications do not require high early-age strengths and may suffer damage from this change. Fig. 1 shows the changes in Blaine fineness of different types of cement from 1950s to 2000 s.

Finer cements are more reactive thus their rheology is harder to control. They also have higher heat of hydration and higher amount of alkalis released [15]. Although the 28-day strength-age curve of a coarse cement may intersect with that of a leaner mix of a fine cement, coarser cements may give an increase in strength of around 25 percent of the 28-day value at one year [18]. On the contrary, leaner mix with finer cement may show little increase after 28 days.

The initial strength in hardened Portland cement is greatly affected by particles smaller than $30 \mu \mathrm{m}$, while particles larger than $60 \mu \mathrm{m}$ have practically "no effect" upon the strength-gain of cement [19], [20].

* Corresponding author: h.karimi@tue.nl 


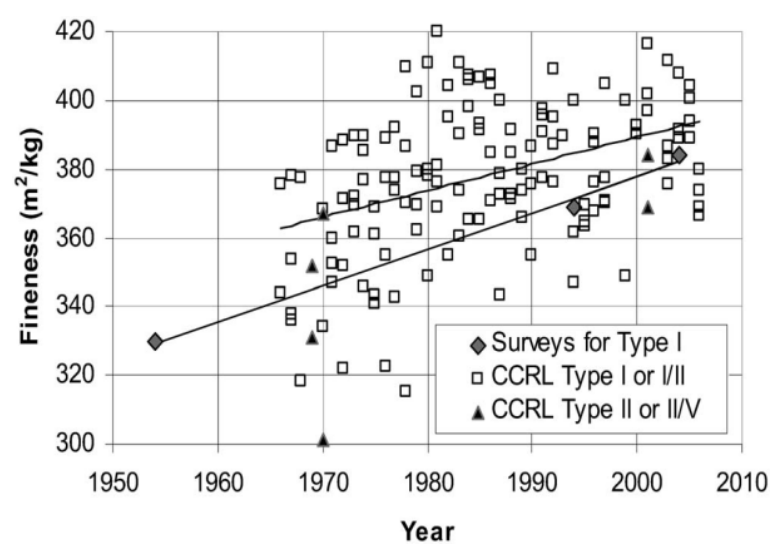

Fig. 1. Trend in cement fineness from 1950s to 2000s [17]

The content of particle fraction smaller than $5 \mu \mathrm{m}$ plays a special crucial role in short-term strength development and the time development of strength is not explicitly a function of the specific surface measured according to Blaine, but a function of the particle size distribution of cements [20]. Wider particle size distributions (PSDs) lead to higher packing density of the system and decreased water demand. On the contrary, narrower PSDs are advantageous from a hydration rate point of view [21], [22]. However, this effect is also a function of the overall water-cement ratio of the mix. As the water-cement ratio is increased, the effect of PSD on the ultimate degree of hydration becomes more significant [23]. It should also be noted that, coarser cements set at lower degree of hydration. Nevertheless, they require more time to achieve set [24].

The reduction in internal relative humidity $(\mathrm{RH})$ of coarser cements is less than finer cements and they usually produce less autogenous shrinkage [24].

This study aims to investigate the effect of the physical structure of cement on mechanical properties of cement pastes. Particle size distribution (PSD) of cement is modified through an airjet screen and the effects of this adjustment on workability, compressive strength, and autogenous shrinkage of cement pastes are evaluated.

\section{Experimental program}

\subsection{Materials and changing PSD}

Ordinary Portland Cement CEM I 52.5 R in combination with a polycarboxylic ether based high-range water reducer admixture (HRWRA), with a dosage of $0.3 \%$ was used to make cement pastes. The properties of OPC CEM I $52.5 \mathrm{R}$ are shown in Table 1.

Table 1. Properties of OPC CEM I 52.5 R

\begin{tabular}{|c|c|c|}
\hline $\begin{array}{c}\text { Compressive } \\
\text { strength } \\
{[\mathrm{MPa}] \text { After } 2} \\
\text { days }\end{array}$ & $\begin{array}{c}\text { Compressive } \\
\text { strength } \\
{[\mathrm{MPa}] \text { After } 28} \\
\text { days }\end{array}$ & $\begin{array}{c}\text { Specific surface } \\
\text { area } \\
\text { (Blaine) }\left[\mathrm{m}^{2} / \mathrm{kg}\right]\end{array}$ \\
\hline$\geq 30$ & $\geq 52,5$ & ca. 450 \\
\hline
\end{tabular}

The water-cement ratio of 0.4 is used to prepare the cement pastes. A laboratory Siebteknik airjet screen SLS is used to modify the particle size distribution of the cement. Feed rate, vacuum pressure, and duration are controlled in the preparation of the modified cement.

\subsection{Particle size analysis}

Considering the relatively small particle size of cements $(<125 \mu \mathrm{m})$, a laser light scattering (LLS) technique (Malvern Mastersizer 2000® PSD analyser) was employed to determine the PSDs of cements. This method uses the feature that the diffraction angle of the laser beam on the particle surfaces is inversely proportional to the particle size. A projection of this diffracted light waves was analysed, and the particle size computed [25]. In the calculation, the spherical particle shape was assumed, as explained in [26]. Based on the ISO standard 13320-1 [27], the powders were measured in liquid dispersion using the Mie scattering model. Because cement can react with water, propan-2-ol was utilized as the dispersion liquid [28].

\subsection{Workability}

The workability of the pastes was investigated using EN 1015-3 [29] as a reference. A Hägermann cone was employed for the slump flow test. Fresh cement pastes are filled in a cone with the geometry shown in Fig. 2. Then, the cone was lifted carefully to allow the paste to flow freely on the glass sheet. Two perpendicular diameters of the spread flow were measured, and their mean regarded as the spread flow diameter.

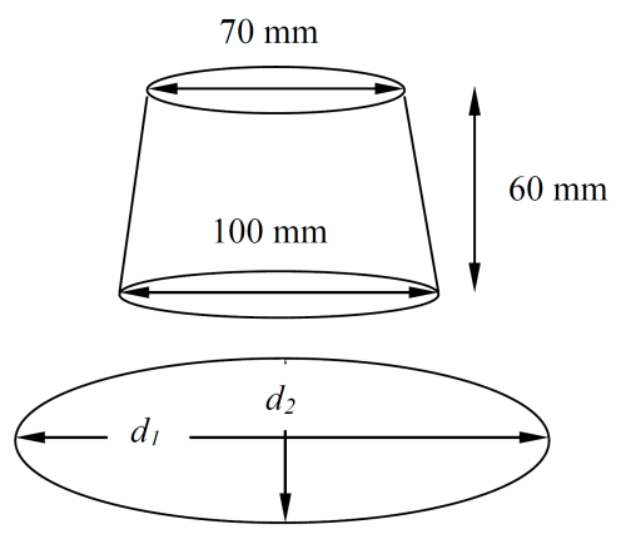

Fig. 2. Geometry of mini-slump test

\subsection{Early-age compressive strength}

Compressive strength tests were performed following EN 196-1: 2005 [30] as a reference. Prism specimens, $40 \times 40$ $\times 160 \mathrm{~mm}^{3}$, were used to measure the effect of the modification of the physical structure of cement on the compressive strengths at 1,3 , and 7 days. All the samples were demoulded approximately $24 \mathrm{~h}$ after casting and then cured in water at about $21{ }^{\circ} \mathrm{C}$. The compressive strength of the specimens was measured at the speed of $2400 \mathrm{~N} / \mathrm{s}$. 


\subsection{Autogenous shrinkage}

Autogenous shrinkage tests were carried out according to the ASTM C1698 [31]. This standard describes a procedure to obtain a free bulk strain of sealed cement pastes under constant temperatures using a dilatometer bench as shown in Fig. 3. Positive strain corresponds to expansion and negative strain to shrinkage. The sealed environment was produced by applying a corrugated tube that offers little resistance to shrinkage or expansion of the samples. The length change of the samples was measured using a dilatometer at arranged time intervals. This method combines the advantages of linear and volumetric volume change measurement methods and through using a plastic mould minimizes moisture loss or gain and maintains a closed system throughout the test [31].

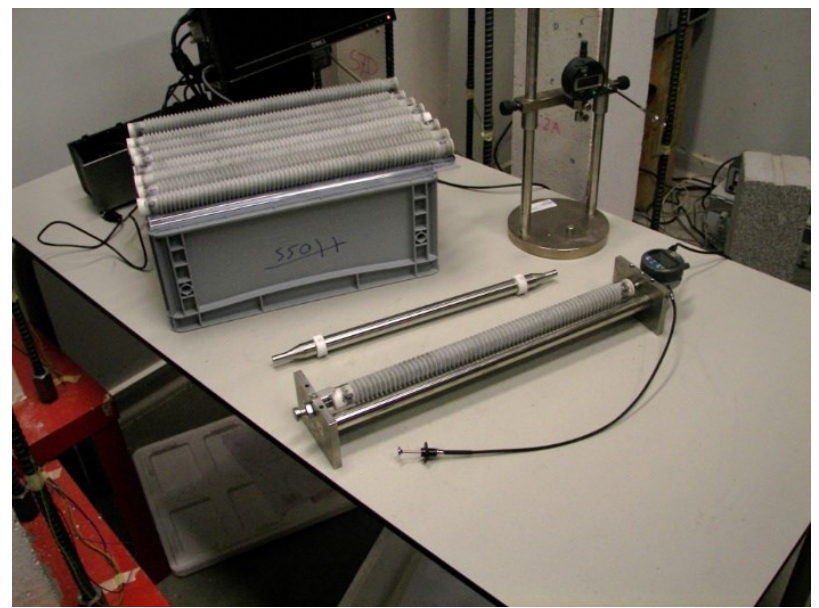

Fig. 3. A suitable dilatometer bench with accessories

\section{Results}

\subsection{Particle size distribution}

The particle size distributions (PSDs) of OPC CEM I 52.5 $\mathrm{R}$ and the modified cement are shown in Fig. 4. CEM I $52.5 \mathrm{R}$ contains no particles larger than $90 \mu \mathrm{m}$ and smaller than $0.3 \mu \mathrm{m}$ and its modal value is $20 \mu \mathrm{m}$. The modified cement has the same minimum, maximum, and modal values but at the same time it is coarser than the OPC cement. The modified cement has more volume fractions of particles bigger than $20 \mu \mathrm{m}$, while the OPC cement has more volume fractions of particles smaller than $20 \mu \mathrm{m}$.

\subsection{Workability}

The effect of cement fineness on the flowability of cement pastes is shown in Fig. 5. The modification of physical structure of cement has led to a coarser cement that is more workable at similar water-cement ratios. This effect can be attributed to the lower amount of particles smaller than $30 \mu \mathrm{m}$, as an increase in such particles leads to deteriorated rheological properties [20]. Another reason can be the difference in the amount of calcium sulphate in the mixtures. After grinding, calcium sulphate is mostly found in the finer part of cement, as it is much softer than clinker. Whereas, the harder $\mathrm{C}_{2} \mathrm{~S}$ is rather found in the coarser fraction of cement [15].

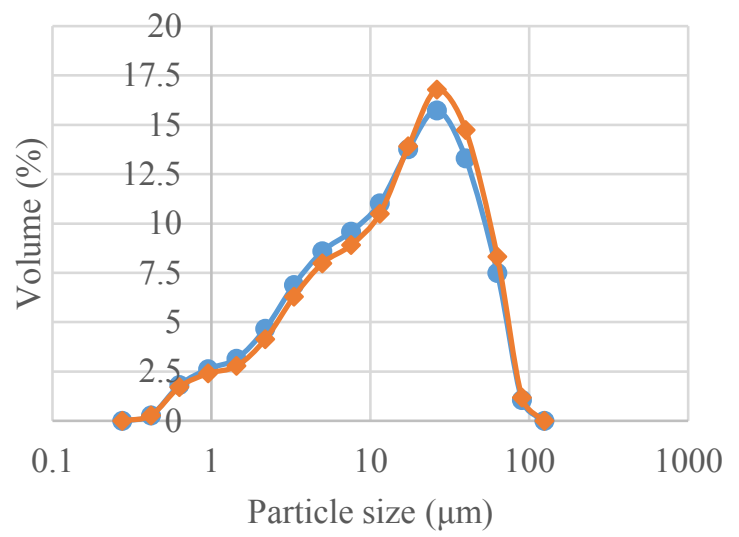

$\multimap$ OPC cement $\multimap$ Modified cement

Fig. 4. PSD of the OPC and the modified cement

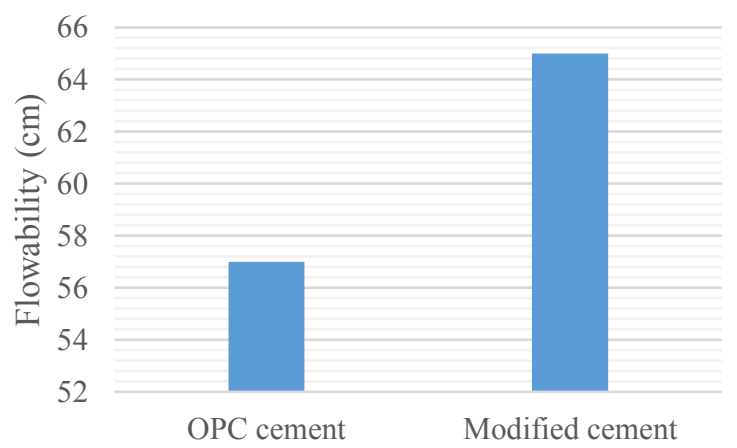

Fig. 5. Flowability of the pastes proportioned with the OPC cement and the modified cement

\subsection{Early-age compressive strength}

The average compressive strength development of the specimens, proportioned with the OPC cement and the modified cement, are presented in Fig. 6. The compressive strength of the modified cement is lower than the OPC cement at similar ages. This can be attributed to the differences in the cement hydration degree. Cement hydration is limited by the availability of water at the cement particle surfaces and this availability is controlled by two factors: the overall water-cement ratio and the particle size distribution [23].

\subsection{Autogenous shrinkage}

The effect of cement coarseness on the autogenous shrinkage of the cement pastes is shown in Fig. 7. The modified cement has lower autogenous shrinkage at similar ages. This can be attributed to the fact that since smaller pores are emptied in the finer cement systems, the autogenous shrinkage of finer cements are much greater than that of coarser cements [17]. Another reason is the creep of concrete, which causes the stress induced by a sustained load to reduce with time. The relaxation - the decrease of stress with time - significantly affect cracking in concrete [32]. The factors underlying strength gain of 
concrete, either cement composition or degree of hydration affect creep and the lower the strength the greater the creep [33].

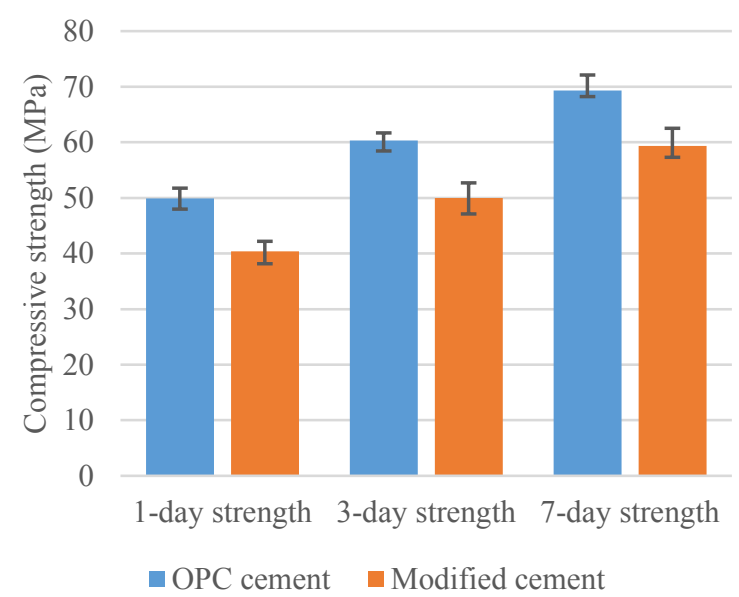

Fig. 6. Early-age compressive strength of pastes

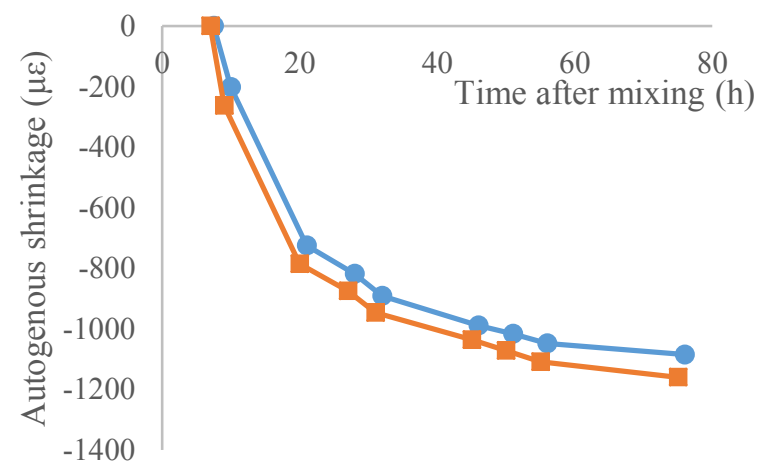

$\longrightarrow$ Modified cement $\quad \rightarrow$ OPC cement

Fig. 7. Linear autogenous shrinkage of cement pastes

\section{Discussion and conclusions}

The particle size distribution of cements has continuously changed over the past 50 years and the trend has been toward increasing fineness of Portland cement [18], [34][36]. Higher early-age strength has been the main incentive for such an approach. However, in some applications durability is far more important than high early-age strength. While concrete made with coarseground cement of the first half of the twentieth century show lesser tendency to drying shrinkage and crazing, today's concrete with finer cements have higher volume change and cracking [34]. The shift from coarser cement to finer cement with higher $\mathrm{C}_{3} \mathrm{~S}$ content has changed the problem of concrete crumbling to concrete cracking over the years [35], [36]. This can be attributed to the fact that cement specifications, in most countries, set only minimum values of fineness, $\mathrm{C}_{3} \mathrm{~S}$ content or strength [18].
The very fine particles are the most important fraction in higher early strengths, and their increase may result in serious problems in terms of volume change, and rheology [20]. There have been efforts to propose ideal particle size distribution of cements to maximize strength [19], [20], [37]. Some researchers have suggested the utilization of coarse cements to decrease autogenous shrinkage [17], [24] or to control the heat of hydration [38]. There have also been efforts to use gap-graded particle size distribution in cements [39], [40].

The aim of this study is to understand the effect of the cement particle size distribution on the mechanical performance and shrinkage of cement pastes. Based on the tests performed and the results obtained the following conclusions can be made:

1- Coarser cements have better rheological properties. This can be beneficial from an economical point of view. In fact, concrete manufacturers can utilize coarser cements in applications that does not require high early strengths while incorporating less highrange water reducing admixture.

2- Coarser cements have lower early-age compressive strengths compared to the finer cements. However, this would not be a shortcoming in applications which usually do not require very high strengths. This lower compressive strength can be beneficial from creep point of view, since the lower the strength, the greater the creep.

3- Autogenous shrinkage of cement pastes made with coarser cements is less than that of finer cements. This can also help concrete manufacturers to make less crack-prone concrete with lower shrinkage while incorporating less chemical admixtures.

\section{References}

[1] Y. Umaki, R. Tomita, F. Hondo, and S. Okada, "Cement composition," US Patent 5181961, 1991.

[2] G. Gelardi, S. Mantellato, D. Marchon, M. Palacios, A. B. Eberhardt, and R. J. Flatt, "Chemistry of chemical admixtures," in Science and Technology of Concrete Admixtures, Elsevier, 2016, pp. 149-218.

[3] J. Schulze and H. Baumgartl, "Shrinkagereducing agent for cement," EP 0308950 A1, 1988.

[4] J. Schulze and H. Baumgartl, "Shrinkagereducing agent for cement," EP0308950 B1, 1988.

[5] N. S. Berke and M. P. Dallaire, "Drying shrinkage cement admixture," US5622558 A, 1995.

[6] F. Wombacher, T. A. Bürge, and U. Mäder, "Method of reducing the shrinkage of hydraulic binders," EP1024120 B1, 2012.

[7] T. Goto, T. Sato, K. Sakai, and M. Ii, "Cementshrinkage-reducing agent and cement composition," US4547223 A, 1985.

[8] S. Akimoto, S. Honda, and T. Yasukohchi, "Additives for cement," US4946904 A, 1990.

[9] ACI Committee 223, 223R-10 Guide for the Use 
of Shrinkage-Compensating Concrete. American Concrete Institute, 2010.

[10] ACI Committee 212, "212.3R-16 Report on Chemical Admixtures for Concrete," 2017.

[11] N. P. Mailvaganam, "15 - Miscellaneous Admixtures," in Concrete Admixtures Handbook, 1996, pp. 939-1024.

[12] O. M. Jensen and P. F. Hansen, "Water-entrained cement-based materials II. Experimental observations," Cem. Concr. Res., vol. 32, no. 6, pp. 973-978, Jun. 2002.

[13] O. M. Jensen and P. F. Hansen, "Water-entrained cement-based materials," Cem. Concr. Res., vol. 31, no. 4, pp. 647-654, Apr. 2001.

[14] M. Collepardi, R. Troli, M. Bressan, F. Liberatore, and G. Sforza, "Crack-free concrete for outside industrial floors in the absence of wet curing and contraction joints," Cem. Concr. Compos., vol. 30, no. 10, pp. 887-891, Nov. 2008.

[15] P.-C. Aitcin, Binders for durable and sustainable concrete. Taylor \& Francis, 2008.

[16] J. (John) Bensted and P. Barnes, Structure and performance of cements. Spon Press, 2002.

[17] D. P. Bentz, G. Sant, and J. Weiss, "Early-Age Properties of Cement-Based Materials. I: Influence of Cement Fineness," J. Mater. Civ. Eng., vol. 20, no. 7, pp. 502-508, Jul. 2008.

[18] A. Neville, "Why We Have Concrete Durability Problems," Spec. Publ., vol. 100, pp. 21-30, Apr. 1987.

[19] G. Frigione and S. Marra, "Relationship between particle size distribution and compressive strength in portland cement," Cem. Concr. Res., vol. 6, no. 1, pp. 113-127, Jan. 1976.

[20] F. Škvára, K. Koláŕ, J. Novotný, and Z. Zadák, "The effect of cement particle size distribution upon properties of pastes and mortars with low water-to-cement ratio," Cem. Concr. Res., vol. 11, no. 2, pp. 247-255, Mar. 1981.

[21] W. Aiqin, Z. Chengzhi, and Z. Ningsheng, "The theoretic analysis of the influence of the particle size distribution of cement system on the property of cement," Cem. Concr. Res., vol. 29, no. 11, pp. 1721-1726, Nov. 1999.

[22] A. Wang, C. Zhang, and N. Zhang, "Study of the influence of the particle size distribution on the properties of cement," Cem. Concr. Res., vol. 27, no. 5, pp. 685-695, May 1997.

[23] D. P. Bentz and C. J. Haecker, "An argument for using coarse cements in high-performance concretes," Cem. Concr. Res., vol. 29, no. 4, pp. 615-618, Apr. 1999.

[24] D. P. Bentz, E. J. Garboczi, C. J. Haecker, and O. M. Jensen, "Effects of cement particle size distribution on performance properties of Portland cement-based materials," Cem. Concr. Res., vol. 29, no. 10, pp. 1663-1671, Oct. 1999.

[25] G. Quercia, "Application of nanosilica in concrete," Eindhoven University of Technology, 2014.

[26] M. Hunger, "An integral design concept for ecological self-compacting concrete," Eindhoven University of Technology, 2010.

[27] S. International Organization for Standardization, CH-1211 Geneve 20, "ISO 13320-1. Particle size analysis-Laser diffraction methods - Part 1: General principles," 2009.

[28] Y. Rui, "Development of sustainable protective Ultra-High Performance Fibre Reinforced Concrete (UHPFRC)," Eindhoven University of Technology, 2015.

[29] "EN 1015-3 Methods of test for mortar for masonry - Part 3: Determination of consistence of fresh mortar (by flow table)," CEN Eur. Comm. Stand., 2007.

[30] EN 196-1, "Methods of testing cement - Part 1: Determination of strength.," CEN Eur. Comm. Stand., 2005.

[31] "ASTM C1698 - 09(2014) Standard Test Method for Autogenous Strain of Cement Paste and Mortar," ASTM.

[32] The Concrete Society, TR22 Non-structural cracks in concrete. 2010.

[33] A. M. Neville, "Role of Cement in the Creep of Mortar," ACI J. Proc., vol. 55, no. 3, pp. 963-984, Mar. 1959.

[34] R. W. Burrows, M-11: The Visible \&amp; Invisible Cracking of Concrete. American Concrete Institute, 1998.

[35] P. Mehta and R. W. Burrows, Building Durable Structures in the 21st Century, vol. 23, no. 3. The Institute, 2001.

[36] P.-C. Aïtcin and S. Mindess, "Back to the Future," Concr. Int., vol. 37, no. 5, pp. 37-40, May 2015.

[37] I. B. Celik, "The effects of particle size distribution and surface area upon cement strength development," Powder Technol., vol. 188, no. 3, pp. 272-276, Jan. 2009.

[38] D. P. Bentz, C. J. Bognacki, K. A. Riding, and V. H. Villarreal, "Hotter Cements, Cooler Concretes," Concr. Int., vol. 33, no. 1, pp. 41-48, Jan. 2011.

[39] T. Zhang, Q. Yu, J. Wei, and P. Zhang, "A new gap-graded particle size distribution and resulting consequences on properties of blended cement," Cem. Concr. Compos., vol. 33, no. 5, pp. 543550, May 2011

[40] T. Zhang, Q. Yu, J. Wei, P. Zhang, and P. Chen, "A gap-graded particle size distribution for blended cements: Analytical approach and experimental validation," Powder Technol., vol. 214, no. 2, pp. 259-268, Dec. 2011. 